\title{
ESTUDOS E PERSPECTIVAS DO CONTATO LINGUÍSTICO NA SALA DE AULA DOCENTE
}

\section{ESTUDIOS Y PERSPECTIVAS DEL CONTACTO LINGÜÍSTICO EN EL AULA DOCENTE}

\section{STUDIES AND PERSPECTIVES OF THE LINGUISTIC CONTACT IN THE TEACHING CLASSROOM}

\author{
David GIMÉNEZ FOLQUÉS ${ }^{1}$ \\ Cristian TUGUES RODRÍGUEZ ${ }^{2}$
}

A la largo de la historia, el contacto lingüístico ha sido un hecho habitual y universal inherente a la evolución de cualquier idioma. En las últimas décadas, la globalización y, por ende, la posibilidad de una mayor comunicación ha permitido que diferentes culturas entren en contacto. De esta manera, el contacto lingüístico ha recibido paulatinamente un mayor interés por parte de la investigación. Asimismo, el ámbito docente no ha quedado exento de este interés, y estudios como Lenguas en contacto (1953), de Uriel Weinreich, inician un camino que ha tomado mayor relevancia en los últimos años.

Según Ayora Esteban (2008) este fenómeno de contacto ha propiciado que en una misma sociedad encontremos dos o más lenguas, lo que conlleva, en más de una ocasión, a situaciones complejas. Estas condiciones excepcionales las encontramos, también, en el aula docente, donde podemos observar situaciones comunicativas en las que existe más de un idioma, por un lado, y, por el otro, estudiantes heterogéneos con contextos idiomáticos diversos. Por lo tanto, este fenómeno requiere un alto grado de reflexión y análisis por parte de la investigación, como trataremos de ofrecer en este trabajo.

Asimismo, el contacto lingüístico provoca fenómenos como la interferencia, el calco, el préstamo o el cambio de código, elementos que pueden ser trabajos y,

\footnotetext{
${ }^{1}$ Universitat de València (UV), Valencia, España. Profesor en el Departamento de Filología Española. ORCID: https://orcid.org/0000-0002-9059-5591. E-mail: david.gimenez-folques@uv.es

${ }^{2}$ Universidade Estadual Paulista (Unesp), Araraquara - SP - Brasil. Leitor de espanhol AECID. ORCID: https://orcid.org/0000-0002-6710-8601. E-mail: cristian.tugues@gmail.com.

Universitat de València (UV), València - Comunitat Valenciana - Espanha. Doutorando do programa de Estudos Hispânicos Avançados. ORCID: https://orcid.org/0000-0002-6710-8601. E-mail: cristuro@alumni.uv.es
} 
probablemente, aprovechados para la correcta enseñanza de las variedades idiomáticas en el aula docente. Posteriormente, surgen nuevas denominaciones para superar la connotación negativa que algunos estudiosos le concedían al término "interferencia" por relacionarlo con el error, y es sustituido, por lo tanto, por términos como “convergencia” (SERRANO, 2011) o "transferencia” (GÓMEZ DEVÍS, 2013). En este espacio de intercambio de fenómenos, el docente debe contemplar la variedad idiomática del contexto donde enseña, además del origen idiomático de sus estudiantes. Hay que tener en cuenta que vivimos en un mundo donde existen cada vez más movimientos migratorios entre las sociedades, lo que provoca que esta temática sea cada vez más visible.

Por ello, vamos a encontrar en este número una reflexión en torno a estos fenómenos en el ámbito de la enseñanza en diferentes situaciones comunicativas, dividida en tres bloques; el primero, con el español como idioma referente en convivencia con el catalán de Valencia en España; el segundo, con el idioma inglés en convergencia con el español, el catalán, o el chino y el último bloque, con el contacto lingüístico entre el español y el portugués.

En el primer bloque, vamos a encontrar investigaciones centradas en la variedad del español de Valencia donde se produce un contacto lingüístico entre el español y el catalán. El primer artículo de este bloque, "La enseñanza de la lengua en sociedades bilingües. Aspectos gramaticales y culturales del español de Valencia”, el profesor del Departamento de Filología Española en la Universitat de València, Jorge Roselló Verdeguer, disemina las características morfológicas, léxicas, y socioculturales del español de Valencia para realizar una propuesta que sirva a aquellos docentes que quieran enseñar esta variedad en el aula de Español como Lengua Extranjera.

En el segundo artículo, "La disponibilidad léxica de los estudiantes de Secundaria de Valencia”, el profesor Marcial Terrádez Gurrea, del Departamento de Filología Española de la Universitat de València, investiga cómo la elección de uno de los dos programas ofertados en un centro de Enseñanza Secundaria en Valencia, el Programa de Enseñanza en Valenciano o el Programa de Incorporación Progresiva, influye en la disponibilidad léxica de sus estudiantes. Hay que tener en cuenta que el valenciano no es tan influyente en la ciudad de Valencia como en otras zonas de la Comunidad Valenciana, por lo que resultará interesante observar cómo influyen estos programas en la variedad de castellano de los estudiantes. 
Para finalizar este primer bloque, encontramos el artículo "El español de Valencia en clase de E/LE. Contexto teórico y metodología" del profesor David Giménez Folqués del Departamento de Filología Española de la Universitat de València. En esta investigación, se incluye el concepto de variedad del español de Valencia y su enseñanza en una experiencia con alumnos estadounidenses que realizaron una estancia en la Universitat de València. Mediante la inclusión de actividades integradas en el curso de E/LE sobre dialectología del español, se comprobará, a través de encuestas sociolingüísticas, el grado de conocimiento de estos estudiantes no solo sobre la variedad del español de Valencia, sino también sobre las diferentes variedades del español.

En el segundo bloque, encontramos la situación comunicativa que se produce entre el inglés y otros idiomas como el chino, el catalán o el español y los fenómenos que se derivan de este contacto, como, por ejemplo, el "Spanglish" en Estados Unidos con un contacto constante entre estos dos idiomas. De este modo, en el primer artículo de esta sección, "Los aspectos morfosintácticos y léxicos del Spanglish en la clase de E/LE en un contexto universitario", Cristian Tugues Rodríguez, investigador de la Universidade Estadual Paulista (UNESP-FCLAr), en Sao Paulo, aborda este mismo fenómeno del "Spanglish" en el ámbito docente, basándose en una experiencia con alumnos universitarios en clase de E/LE. Asimismo, llevará a cabo un enfoque didáctico mediante una unidad docente para mostrar cómo esta variedad del español estadounidense tiene características propias y cómo se pueden transmitir a los estudiantes mediante actividades prácticas.

En el segundo artículo de este bloque, "Dificultades en la competencia oral de estudiantes de Educación Secundaria en una sociedad bilingüe con dos lenguas en contacto: el caso de la enseñanza de inglés a hablantes de catalán y español”, la autora, Celia Gutiérrez Villar, profesora de Educación Secundaria Obligatoria en Cataluña, en INS Montsià, analiza "cómo el inglés se adquiere en una sociedad donde existe un contacto lingüístico entre el catalán y el español" desde la perspectiva de la competencia lingüística oral, confiriendo una especial atención en la interacción idiomática entre los estudiantes y la actitud con respecto a esta situación.

El tercer artículo de este bloque "La ansiedad en el proceso de enseñanza/aprendizaje de español lengua extranjera y su relación con el contacto lingüístico en contexto de inmersión”, la profesora Dayane Mónica Cordeiro, del Departamento de Letras de Español en la Universidade Federal de Pernambuco - 
(UFPE), en Pernambuco, expone los resultados obtenidos en una investigación realizada con estudiantes estadounidenses en Valencia en un contexto de inmersión lingüística en español. Específicamente realiza un estudio en dos etapas, el inicio y el final de un curso de E/LE, comprobando si el contacto lingüístico entre el inglés y el español "ejerce alguna influencia en la ansiedad idiomática" del estudiante.

En último lugar, en el cuarto y último artículo de este segundo bloque, "Interferencia lingüística del inglés en estudiantes chinos de español. El caso de estudiantes universitarios en España". El profesor Carles Navarro Carrascosa, del Departamento de Filología Española en la Universitat de València, plantea un estudio de convergencia entre tres idiomas, el inglés, el español y el chino. En este caso, "se busca la influencia que puede haber tenido el inglés, como L2, en el español, como L3". Para llevar a cabo este trabajo, realiza un estudio comparativo entre alumnos chinos en clase de E/LE, en España, que están realizando un curso preuniversitario, en primer lugar, y, en segundo lugar, con estudiantes estadounidenses que realizaron una estancia de un semestre en el mismo país. El objetivo es el de observar qué errores pertenecen a la influencia del inglés en los estudiantes sinohablantes analizados.

Finalmente, en el tercer bloque que, además, cierra este número encontraremos el artículo "Lenguaje y aprendizaje: la atenuación en portugués y en español”. En este caso, el profesor Jorge Martí Contreras, del Departamento de Filología y Culturas Europeas en la Universitat Jaume I (UJI), presenta un análisis intralingüístico e interlingüístico donde se analiza la aparición del fenómeno de la atenuación en español y portugués en un contexto de aprendizaje de L2. Para llevar a cabo su cometido introducirá los elementos que componen este ámbito pragmático y culminará la investigación con una secuencia didáctica mediante un análisis comparativo entre ambas lenguas.

\section{REFERENCIAS}

AYORA ESTEBAN, M. ${ }^{a}$ C. La situación sociolingüística de Ceuta: un caso de lenguas en contacto. Revista Tonos, 16, 2008. Disponible en https://www.um.es/tonosdigital/znum16/secciones/tritonos1-Ceuta.htm.

GÓMEZ DEVÍS, B. Fenómenos frecuentes en el contacto lingüístico castellano-catalán (en su variedad valenciano). En GÓMEZ MOLINA, J. R. El español de Valencia.

Estudio sociolingüístico. Berna: Peter Lang, p. 347-370, 2013.

SERRANO, M. J. Sociolingüística. Barcelona: Edicones del Serbal, 2011. 
WEINREICH, U. Lenguas en contacto. Descubrimientos y problemas. Venezuela: Ediciones de la Universidad Central, 1953.

\section{Cómo citar este artículo}

GIMÉNEZ FOLQUÉS, David; TUGUES RODRÍGUEZ, Cristian. Estudios y perspectivas del contacto lingüístico en el aula docente. Rev. EntreLínguas, Araraquara, v. 5, n. esp. 1, p. 232-236, jul., 2019. E-ISSN: 2447-3529. DOI: 10.29051/el.v5iesp.1.12990

Submetido em: 01/06/2019

Aprovado em: 30/06/2019

Publicado em: 01/10/2019 